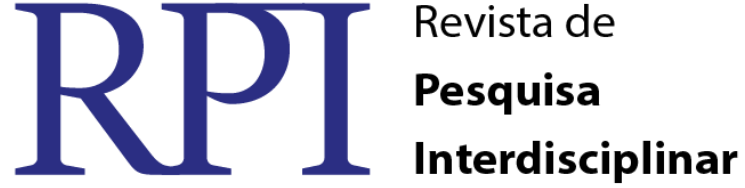

\section{OBJETOS EDUCACIONAIS PARA O ENSINO SUPERIOR DE QUÍMICA DISPONÍVEIS NO BANCO INTERNACIONAL DE OBJETOS EDUCACIONAIS (BIOE): UM ESTUDO CASO PARA QUIIMICA GERAL I}

\author{
Felícia Maria Fernandes de Oliveira - UFCG/CFP/UACEN \\ Edilson Leite da Silva - UFCG/CFP/UACEN
}

\begin{abstract}
RESUMO
No cenário atual de constante evolução das informações, surge as Novas Tecnologias da Informação e Comunicação como aliada no processo ensino aprendizagem em todas as áreas do conhecimento. Os avanços tecnológicos, principalmente depois da abertura comercial da internet, permitiram o desenvolvimento de diversas ferramentas educativas, como os objetos de aprendizagem, dentre outras, que tornam o ensino interativo e dinâmico, apresentando conteúdos digitais que podem ser utilizados nas diversas áreas do conhecimento, mas ainda desconhecidos e/ou não utilizado por muitos docentes e discentes. A presente pesquisa centra-se em apresentar os objetos educacionais de aprendizagem para o ensino superior de química, disponíveis no Banco Internacional de Objetos Educacionais, dando ênfase aos conteúdos do componente curricular Química Geral I. Quanto à metodologia é uma pesquisa aplicada, pois gera conhecimento para aplicação prática ao apresentar objetos de aprendizagem para auxiliar no processo de ensino de conteúdos de Química Geral I, em relação a abordagem é qualitativa e qualitativa, pois apresenta as informações por métodos matemáticos e/ou estatísticos, quanto por meio de uma análise mais detalhado dos fatos que não pode traduzir-se em número, também é um estudo de caso, pois aborda os objetos de educacionais do Banco Internacional de Objetos Educacionais, dentre outros repositórios existentes. A presente pesquisa contribui com docentes e/ou discentes ao apresentar os objetos de aprendizagem disponíveis no Banco Internacional de Objetos Educacionais que podem ser utilizados no processo de ensino aprendizagem de Química Geral I, mostrando as suas quantidades e como estão organizados no repositório de acordo com as suas categorias que são animações/simulações, áudios, experimentos práticos, hipertextos, imagens, mapas, softwares educativos e vídeos.
\end{abstract}

Palavras-Chave: Objetos de aprendizagem. Ensino Superior. Ensino de Química

\section{EDUCATIONAL OBJECTS FOR HIGHER EDUCATION IN CHEMICAL AVAILABLE IN THE BANK INTERNATIONAL EDUCATIONAL OBJECTS (BIOE): A CASE STUDY FOR GENERAL CHEMISTRY I CLASSES.}

\footnotetext{
ABSTRACT

In the present scenario of constantly changing information, the New Information and Communication Technologies come as an ally in the learning process in all knowledge areas. Especially after the trade internet openness, technological advances have allowed the development of various educational tools, such as learning objects that make interactive and dynamic teaching, presenting digital contents that can be used in various knowledge areas, but still unknown and/or not used by many teachers and students. This research focuses on presenting the educational learning objects for higher education in Chemistry available at the International Bank of Educational Objects, emphasizing the contents of General Chemistry I classes. The methodology is an applied research because it generates knowledge for practical application by presenting learning objects to assist in the teaching of General Chemistry I contents. This research adopts a quali-quatitative approach that
} 
presents the information by mathematical and/or statistical methods and a more detailed analysis of the facts that cannot be translated into numbers, and it is also a case study because it focuses on the educational objects of the International Bank of Educational Objects from other existing repositories. This paper aims to contribute to teachers and/or students presenting learning objects available in the International Bank of Educational Objects that can be used in the General Chemistry I teachinglearning process, showing their amounts and how they are organized in the repository in accordance with their categories such as animations/simulations, audio, practical experiments, hypertext, images, maps, educational software and videos.

Keywords: Learning objects; Higher education; Chemistry teaching.

\section{INTRODUÇÃO}

A sociedade está cada vez mais globalizada e informatizada. Com a utilização dos computadores o homem vem desenvolvendo papéis cada vez mais importantes no dia a dia da sociedade e na educação. $\mathrm{O}$ discernimento desse crescimento está acontecendo principalmente entre os jovens. De acordo com Kenski (2011, p. 22), "um novo tipo de sociedade tecnológica é determinado principalmente pelos avanços das tecnologias digitais [...]."

Frente às novas tecnologias, os profissionais da educação deparam-se com exigências no sentido de introduzirem à sua pratica docente as Novas Tecnologias da Informação e Comunicação (NTIC), segundo (SAMPAIO; LEITE, 2008, p.14) hoje a "informação e o conhecimento possuem diversas formas de transmissão e quase todas elas utilizam tecnologia: computador, satélite, terminal de banco, fax, mídia, multimídia etc. “ Desse modo o autor afirma que " mesmo as populações mais desfavorecidas entram em contato com a maioria destas formas de transmissão de conhecimento e informação"

Existem diversas tecnologias que podem ser usadas na educação como as ferramentas de comunicação, sistemas de busca, base de dados, os jogos educativos, os objetos educacionais, etc. Mas, mesmo neste contexto atual ainda encontramos professores contrários ao uso das tecnologias na educação, assim como elucida (AREA, 2006, p.168) os professores pertencem a um grupo "que por sua idade, foi alfabetizado culturalmente na tecnologia e formas culturais impressas". E por ser nesse modus operandis, o professor se apropriou da cultura "pela palavra escrita, pensamento academicamente textualizado, o cheiro de papel, a biblioteca como cenários do saber $[\ldots .$.$] ".$

No ensino de Química existem varias ferramentas que podem auxiliar no processo ensino-aprendizagem, como os Objetos Virtuais de Aprendizagem (OVA). A área de Ciências 
Exatas e da Terra é a que apresenta maior quantidade de Objetos de aprendizagem. Para o ensino superior de Química o Banco Internacional de Objetos Educacionais (BIOE) disponibiliza 9206 Objetos. Este nível de ensino encontra-se subdividido em 9 áreas: Ciências Agrárias, Ciências Biológicas, Ciências da Saúde, Ciências Exatas e da Terra, Ciências Humanas, Ciências Sociais Aplicadas, Engenharias, Linguística, Letras e Artes e Multidisciplinar. Podendo ser acessado clicando em educação superior e/ou digitando diretamente na barra de endereço do navegado o link http://objetoseducacionais2.mec.gov.br/handle/mec/3822.

De acordo com Leite (2009, p. 13) "os Repositórios constituem de fato inovação no sistema de comunicação da ciência e no modo como a informação - aquela que alimenta e resulta das atividades acadêmicas e científicas - é gerenciada". Diante desse contexto, este trabalho apresenta para alunos e professores objetos de aprendizagem do Banco Internacional de Objetos Educacionais, que podem ser utilizados no ensino superior de química, especificamente no componente curricular de Química Geral I.

\section{Desenvolvimento}

Diante de uma sociedade cada vez mais globalizada, a qual chamamos de sociedade da informação e do conhecimento, com aceleradas e profundas transformações tecnológicas, educacionais e informacionais, as NTICs possibilitam apoio na prática pedagógica, no ensino e na pesquisa, mediada por computadores e o uso de recursos digitais, possibilita criar um novo cenário para a transmissão do conhecimento e afetam o funcionamento $\mathrm{e} o$ desenvolvimento qualitativo dos ambientes educacionais.

A utilização da informática no processo de ensino aprendizagem no Brasil passou a ser objeto de estudo no final da década de 1970, por meio do projeto Educação com Computador (EDUCOM) - o qual se constituiu como afirma Rodrigues $(2009$, p.3): “[...] a primeira ação oficial e concreta para levar os computadores até as escolas publicas".

Diante das necessidades da implantação consciente das novas tecnologias nas salas de aula, entre outros programas, o MEC criou outros programas como o ProInfo e o ProInfo Integrado, este sendo, um programa de formação continuada voltada para o uso didáticopedagógico das NTICs nas salas de aulas, de acordo com à distribuição dos equipamentos 
tecnológicos nas escolas (computadores, data show, DVD, televisor) e possibilita o conhecimento à oferta de conteúdos e recursos multimídia e digitais oferecidos pelos sites como Portal do Professor, TV Escola e DVD Escola, Domínio Público e BIOE.

No mesmo ano o MEC em parceria com Rede Latinoamericana de Portais Educacionais (RELPE), Organização dos Estados Ibero-americanos (OEI) e outros o Ministério da Ciência e Tecnologia (MCT) criou o BIOE, com a finalidade de compartilhar recursos educacionais digitais de acesso livre em todos os níveis e modalidades de ensino. São 19.842 objetos publicados e 174 sendo avaliados ou aguardando autorização dos autores para serem publicados, disponíveis o acesso isoladamente ou em coleções, os quais os recursos estão organizados por disciplinas e em seguida por categorias dos objetos ${ }^{1}$.

Nas ultimas duas décadas de acordo com a legislação os currículos dos cursos de licenciatura em Química sofreram diversas modificações, visando formar profissionais antenados e sintonizados com as necessidades de uma sociedade cada vez mais atualizada e informatizada. Afirmam Zucco; Pessine; Andrade (1999, p.459) "Entretanto, as modificações eram superficiais, limitando-se à inclusão de novas disciplinas, extinção de outras ou apenas realizando remanejamentos nas respectivas grades curriculares".

Segundo Zucco; Pessine; Andrade (1999) as diretrizes para os currículos dos cursos de Química devem ter como objetivo formar profissionais que sejam mediadores da aprendizagem, sistematizadores de ideias, facilitadores do conhecimento, que deem ênfase ao raciocínio logico e não apenas ao fornecimento de um grande numero de informações, além de serem profissionais críticos e reflexivos, capaz de exercitar sua criatividade na resolução de problemas, auxiliar os estudantes a adquirir conhecimentos químicos e conhecer as dificuldades relacionadas a essa aquisição e assim buscar métodos para a resolução de problemas frente ao processo educacional. Neste contexto Moreira (1997, p.6) "Percebe-se que o currículo envolve apresentação de conhecimentos e inclui um conjunto de experiências de aprendizagem que visam favorecer a assimilação e a reconstrução desses conhecimentos por parte dos alunos".

O currículo de licenciando em Química envolve o domínio de conhecimentos nas áreas de matemática, física e biologia. Deve proporcionar a licenciando conhecimento e capacidade de analisar o material didático-pedagógico relacionados à Educação Química e a legislação concernente as políticas públicas educacionais.

\footnotetext{
${ }^{1}$ Cf. Endereço eletrônico http://objetoseducacionais2.mec.gov.br/
}

RPI Revista de Pesquisa Interdisciplinar, Cajazeiras, v. 1, Ed. Especial, 390 - 401, set/dez. de 2016. 
A disciplina Química Geral I tem por objetivo proporcionar ao individuo uma melhor aprendizagem dos conteúdos abordados no decorrer do curso; desenvolver a contextualização dos conteúdos de forma teórica e relacioná-los com situações do cotidiano. Com base no plano de curso de Química/UFCG/CFP estão divididos nos seguintes conteúdos: Estequiometria, Gases e Soluções.

A partir de 2011, foram ofertadas pelo curso de Licenciatura em Química do CFP/UFCG, seis turmas de Química Geral I, sendo 5 para as turmas de Química e 1 para as turmas de Química e Física, como mostra no quadro 1.

Quadro 1 - Alunos de Química Geral I de 2011.1 a 2015.1

\begin{tabular}{|c|c|c|c|c|c|c|c|c|}
\hline $\begin{array}{c}\text { TURMA } \\
\text { S }\end{array}$ & $\begin{array}{c}\text { PERÍO } \\
\text { DOS }\end{array}$ & $\begin{array}{c}\text { MATRICU } \\
\text { LADOS }\end{array}$ & $\begin{array}{c}\text { REPROV } \\
\text { ADOS }\end{array}$ & $\begin{array}{c}\text { REPROVADOS } \\
\text { POR FALTA }\end{array}$ & $\begin{array}{c}\text { TRANCA } \\
\text { DOS }\end{array}$ & $\begin{array}{c}\text { CANCE } \\
\text { LADOS }\end{array}$ & $\begin{array}{c}\text { APROV } \\
\text { ADOS }\end{array}$ & $\begin{array}{c}\% \text { DE } \\
\text { APROVADOS }\end{array}$ \\
\hline Química & 2011.1 & 40 & 20 & 9 & 1 & 1 & 10 & $25 \%$ \\
\hline Física & 2011.1 & 39 & 21 & 0 & 0 & 0 & 18 & $46 \%$ \\
\hline $\begin{array}{l}\text { Química } \\
\text { E Física }\end{array}$ & 2012.1 & 25 & 6 & 2 & 0 & 1 & 16 & $64 \%$ \\
\hline Química & 2012.1 & 39 & 13 & 18 & 1 & 1 & 7 & $17,9 \%$ \\
\hline Química & 2014.1 & 46 & 28 & 5 & 2 & 2 & 11 & $23,9 \%$ \\
\hline Química & 2015.1 & 52 & 15 & 18 & 1 & 3 & 15 & $28,8 \%$ \\
\hline
\end{tabular}

Fonte: Próprio autor (2016)

De acordo com o quadro 1, observa-se que o baixo percentual aprovados durante estes semestres (2011.1 a 2015.1), visto que em apenas um desses semestres os aprovados na disciplina superaram os $50 \%$, enquanto isso, quatro semestre o índice de aprovação foi inferior a 30\%. Estes dados demonstram a necessidade de estudo no sentido de apontar alternativas que possam contribuir para reverter esta situação, como por exemplo o uso dos OVAs, como os apresentados neste trabalho.

\section{Metodologia}

Nesta pesquisa o intuito é apresentar os Objetos Virtuais de Aprendizagem para ensino superior de Química, fundamentando-se em estudos desenvolvidos por autores na área de 
aplicação. Em seguida, optou-se por fazer uma pesquisa dos OVAs disponíveis no BIOE para o Ensino Superior de Química, que poderão serem aplicados para suprir dificuldades frente aos conteúdos em Química Geral I.

Quanto à natureza é uma pesquisa aplicada, Prodanov (2013, p.51) elucida que neste tipo de pesquisa "objetiva gerar conhecimentos para aplicação prática dirigida à solução de problemas específicos. Envolve verdades e interesses locais." Analisando os objetos disponíveis no BIOE, estudo esse feito em cima de uma realidade local do curso de Licenciatura em Química UFCG/CFG, o qual apresenta um número considerável de reprovação.

Embasados na literatura e tendo como base de estudo o BIOE, realizou-se uma pesquisa quali-quantitativa. Para Fonseca (2002, p. 20):

\begin{abstract}
A pesquisa quantitativa recorre à linguagem matemática para descrever as causas de um fenômeno, as relações entre variáveis, etc. A utilização conjunta da pesquisa qualitativa e quantitativa permite recolher mais informações do que se poderia conseguir isoladamente.
\end{abstract}

A pesquisa qualitativa tem por objetivo apresentar o sentido dos fenômenos do mundo real, compreendendo um conjunto de técnicas interpretativas que destinam-se a expor os componentes de um sistema abstruso de significados. Já a quantitativa busca expor e descrever as informações por meios matemática e ou estatísticos.

Quanto aos procedimentos metodológicos/técnicos o presente trabalho consiste em levantamento bibliográfico, estudo de caso: o levantamento bibliográfico feito principalmente em artigos, livros, monografias, dissertações e teses, físicos e/ou digitais. Segundo Prodanov (2013 p. 54) uma pesquisa bibliográfica é “[...] elaborada a partir de material já publicado, constituído principalmente de: livros, revistas, publicações em periódicos e artigos científicos, jornais, boletins, monografias, dissertações, teses, material cartográfico, internet, [...]”.

Quanto ao estudo de caso, coleta e avalia as informações sobre pessoas, grupos, com a finalidade de estudar aspectos peculiares, diante da linha de pesquisa. Gil (2010, p. 37) elucida que o estudo de caso "consiste no estudo profundo e exaustivo de um ou mais objetos, de maneira que permita seu amplo e detalhado conhecimento."

Posteriormente os dados coletados são dispostos em forma de figuras e quadros, explanando quantos e quais objetos são disponibilizados no ensino superior de Química que RPI Revista de Pesquisa Interdisciplinar, Cajazeiras, v. 1, Ed. Especial, 390 - 401, set/dez. de 2016. 
podem ser utilizados como ferramenta para o componente curricular Química Geral I, mostrando também como acessar o BIOE.

\section{Resultados e Discussão}

No BIOE os OVAs estão organizados por nível de ensino, são eles: Educação Infantil, Ensino Fundamental subdividido em séries iniciais e séries finais, Ensino Médio, Educação Profissional, Educação Superior e Modalidades de Ensino, esta subdividida em Educação de Jovens e Adultos (EJA) e Educação Escolar Indígena.

No BIOE cada nível esta subdividido em seus referentes componentes curriculares, oferecendo recursos educacionais digitais em todos os níveis de ensino. Recursos estes organizados por sequencia: disciplina e categorias dos objetos, que podem ser acessados pelo endereço eletrônico http://objetoseducacionais2.mec.gov.br/.

Para se ter acesso ao nível de ensino educação superior, na página principal, clica-se na imagem educação superior e/ou digitando diretamente na barra de endereço do navegado o link http://objetoseducacionais2.mec.gov.br/handle/mec/3822 como observa-se no passo 1 na figura 1. Este disponibiliza um total de recursos de 9206 objetos e esta subdividido em 9 áreas: Ciências Agrárias, Ciências Biológicas, Ciências da Saúde, Ciências Exatas e da Terra, Ciências Humanas, Ciências Sociais Aplicadas, Engenharias, Linguística, Letras e Artes e Multidisciplinar.

Em seguida clica-se em Ciências Exatas da Terra, como observa-se no passo 2, sendo a modalidade de ensino que apresenta maior quantidade de recursos, com e 3321. Estando subdividida em: Astronomia (332), Ciência da Computação (07), Física (1074), GeoCiências (70), Matemática (1414), Oceanografia (32), Probabilidade e Estatística (22) e Química (370). No passo 3 clica-se em Química (370) ou através do link http://objetoseducacionais2.mec.gov.br/handle/mec/3831, sendo que para o Ensino Superior de Química o BIOE fornece 370 objetos considerando suas categoria: Animações/Simulações (57), Áudios (18), Experimentos Práticos (30), Hipertextos (0), Imagens (127), Mapas (0), Softwares Educacionais (24) e Vídeos (114). 


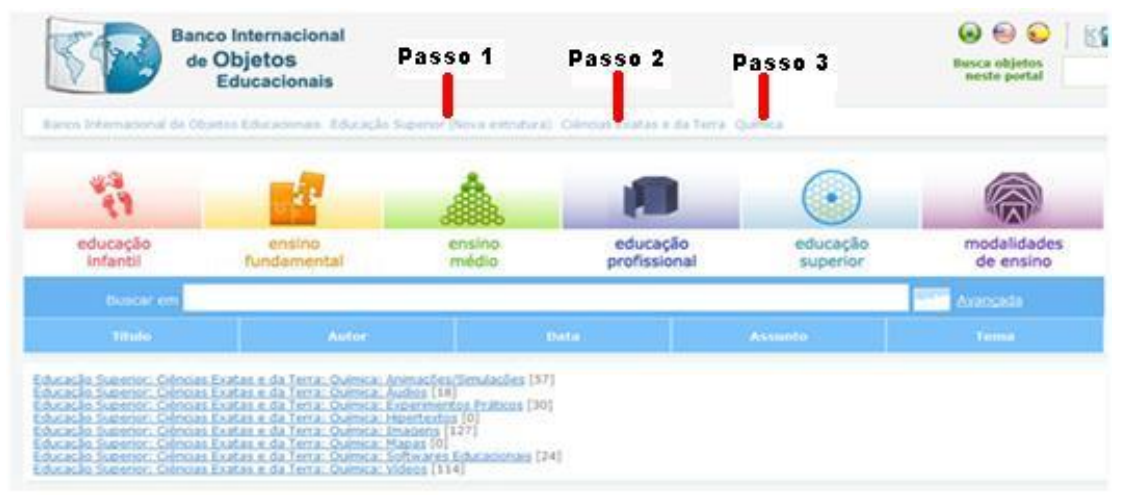

Fonte: BIOE. Acesso em: 04 de agosto de 2016

Figura 1 - Subdivisões da área Ciências Exatas e da Terra.

Como exemplo, ao clicarmos em Animações/Simuladores encontra-se 57 simuladores oferecidos para esta categoria, distribuídos em um total de 3 paginas, sendo que as duas primeiras paginas possui 20 objetos cada uma e a ultima pagina possui 17 objetos. Observase que os objetos nas páginas desta categoria, estão organizados pela ordem alfabética dos seus títulos.

No quadro 2, estão listados os simuladores que abordam os três conteúdos do componente curricular Química Geral I, apresentando o título, autor(es) e o conteúdo ao qual está relacionado. No BIOE, além dessas informações também é possível saber a data de publicação e o tamanho do arquivo referente a cada objeto.

Quadro 2 - Simuladores do BIOE para o ensino de Química Geral I.

\begin{tabular}{|l|l|l|}
\hline Título & Autores & Conteúdo \\
\hline $\begin{array}{l}\text { Atomicabsorptionspectrosc } \\
\text { opy }\end{array}$ & Chasteen, Thomas G & Estequiometria \\
\hline $\begin{array}{l}\text { Conformation energy } \\
\text { profile for butane C2-C3 } \\
\text { bond rotation }\end{array}$ & Leaners TV & Estequiometria \\
\hline $\begin{array}{l}\text { Conformation energy } \\
\text { profile for cyclohexane ring } \\
\text { flip }\end{array}$ & Learners TV & Estequiometria \\
\hline $\begin{array}{l}\text { Conformation energy } \\
\text { profile for ethane }\end{array}$ & Learners TV & Estequiometria \\
\hline $\begin{array}{l}\text { Dosage d'une acide fort par } \\
\text { une base fort* }\end{array}$ & Mentrard, Daniel & Soluções \\
\hline $\begin{array}{l}\text { Dosage d'une acide fort par } \\
\text { une base fort* }\end{array}$ & Mentrard, Daniel & Soluções \\
\hline $\begin{array}{l}\text { Electron density vsinternucleaEearnersTV } \\
\text { distance }\end{array}$ & Bernstein, Any & Estequiometria \\
\hline Estereoisômero & Araújo, Gabriel Cremasco & Estequiometria \\
\hline Estereoisômeros: exercício & Fiscarelli, Sílvio Henrique & Estequiometria \\
\hline $\begin{array}{l}\text { Estrutura dos sólidos (1) - } \\
\text { cúbica }\end{array}$ & Fiscarelli, Sílvio & Soluções \\
\hline Estrutura dos sólidos (2) - &
\end{tabular}

RPI Revista de Pesquisa Interdisciplinar, Cajazeiras, v. 1, Ed. Especial, 390 - 401, set/dez. de 2016. 


\begin{tabular}{|c|c|c|}
\hline tetragonal & Henrique & \\
\hline $\begin{array}{l}\text { Estrutura dos sólidos (4) - } \\
\text { romboédrico-triclínico }\end{array}$ & Fiscarelli, Sílvio Henrique & Soluções \\
\hline $\begin{array}{l}\text { Estrutura dos sólidos (5) - } \\
\text { hexagonal }\end{array}$ & Sílvio Henrique Fiscarelli & Soluções \\
\hline $\begin{array}{l}\text { Estrutura dos sólidos (6) - } \\
\text { monoclínico }\end{array}$ & Fiscarelli, Sílvio Henrique & Soluções \\
\hline Forma da Molécula & $\begin{array}{l}\text { Perkins, Kathy; Chamberlain, Julia; } \\
\text { Moore, Emily; Lancaster, Kelly; } \\
\text { Olson, Jonathan }\end{array}$ & Estequiometria \\
\hline Beer's Law Lab & $\begin{array}{l}\text { Perkins, Kathy; Moore, Emily B.; Lancaster, } \\
\text { Kelly; Malley, Chris; Chamberlain, Julia }\end{array}$ & Soluções \\
\hline $\begin{array}{l}\text { Millikan Oil Drop } \\
\text { experiment }\end{array}$ & LearnersTV & Estequiometria \\
\hline $\begin{array}{l}\text { Modelos do átomo de } \\
\text { hidrogênio }\end{array}$ & $\begin{array}{l}\text { Adams, Wendy; Dubson, Michael; Malley, Chris; } \\
\text { McKagan, Sam; Perkins, Kathy; Wieman, Carl; } \\
\text { Gratny, Mindy }\end{array}$ & Estequiometria \\
\hline Molécula DNA & Fiscarelli, Sílvio Henrique & Estequiometria \\
\hline $\begin{array}{l}\text { Molecular View of } \\
\text { Solution Formation }\end{array}$ & LearnersTV & Estequiometria \\
\hline O efeito estufa & $\begin{array}{l}\text { Adams, Wendy; Blanco, John; Lancaster, Kelly; } \\
\text { LeMaster, Ron; Loeblein, Trish; Parson, Robert; } \\
\text { Perkins, Kathy; Wieman, Carl }\end{array}$ & Gases \\
\hline Properties of Gases & LearnersTV & Gases \\
\hline Sais e solubilidade & $\begin{array}{l}\text { Harlow, Danielle; Perkins, Kathy; Loeblein, Trish; } \\
\text { LeMaster, Ron; Koch, Linda; Adams, Wendy }\end{array}$ & Soluções \\
\hline $\begin{array}{l}\text { Visualisation of hybrid } \\
\text { orbitals from C atomic } \\
\text { orbitals }\end{array}$ & LearnersTV & Estequiometria \\
\hline Vr molécules & Couture, Marc & Estequiometria \\
\hline
\end{tabular}

Fonte: Próprio autor (2016)

*Dois simuladores com nomes iguais, mas que se referem às conteúdos distintos.

No quadro 3, é apresentada a quantidade de objetos referente aos três principais assuntos abordos no componente curricular Química Geral I.

Quadro 3: Total de Simuladores do BIOE para o ensino de Química Geral I.

\begin{tabular}{|l|c|c|c|c|}
\hline Conteúdos & Estequiometria & Soluções & Gases & Total Geral \\
\hline Quantidade & 14 & 9 & 2 & 25 \\
\hline
\end{tabular}

Fonte: Próprio autor (2016)

Para obter mais informações sobre um determinado objeto, ao clicar no seu título, será aberta uma nova sobre com todas as informações do objeto escolhido. Por exemplo, escolher o objeto Properties of Gases, aparece a figura 2. A mesma descreve todas as informações referentes ao objeto como o título, tipo de recurso, objetivo, descrição, observação, componente curricular, tema, autores, idioma, país, fonte, endereço eletrônico, detentor dos RPI Revista de Pesquisa Interdisciplinar, Cajazeiras, v. 1, Ed. Especial, 390 - 401, set/dez. de 2016. 
direitos autorais, tipo de licença, quem submete, URI, onde esta disponível, sendo possível também baixar o plugin necessário para a visualização do recurso na própria pagina do BIOE. De forma congênere, ao selecionar qualquer outro objeto de qualquer uma das categorias no BIOE, estas informações serão apresentadas.

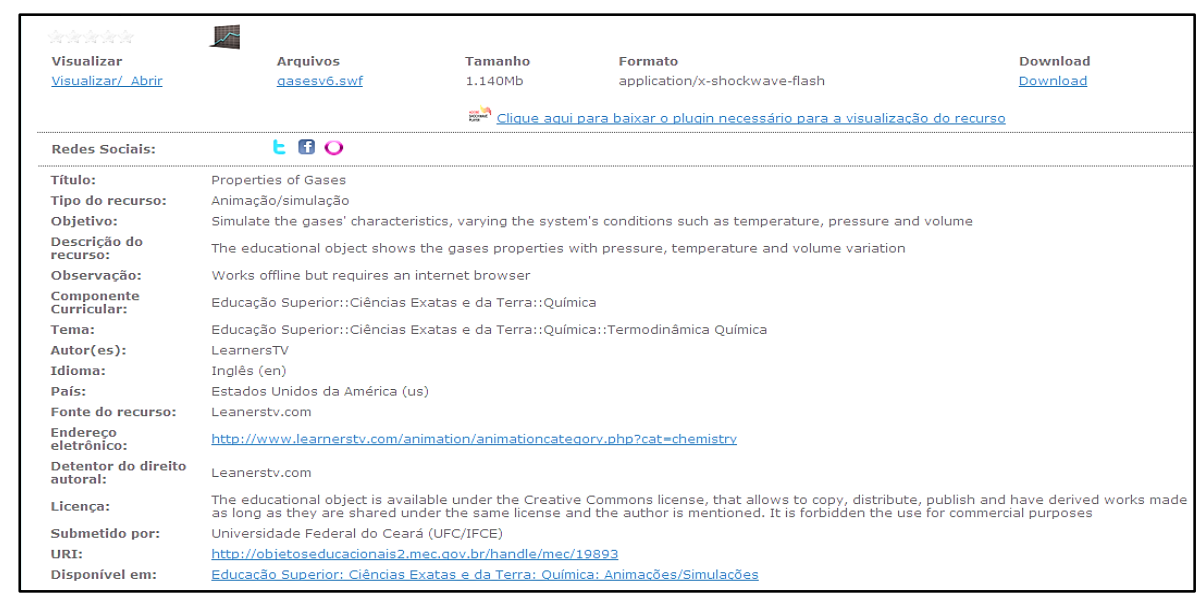

Fonte: BIOE. Acesso em: 21 de agosto de 2016

Figura 2 - Mostra as Informações sobre o Objeto Properties of Gases

No quadro 4 estão apresentados o total de cada objeto de aprendizagem para a componente curricular Química Geral I, disponíveis no BIOE.

Quadro 4 - Total de Objetos do BIOE para o ensino de Química Geral I.

\begin{tabular}{|c|c|c|c|c|c|c|c|c|c|}
\hline Objetos & $\begin{array}{c}\text { Animação/ } \\
\text { Simulação }\end{array}$ & $\begin{array}{c}\text { Áudi } \\
\text { os }\end{array}$ & $\begin{array}{c}\text { Experimentos } \\
\text { Práticos }\end{array}$ & $\begin{array}{c}\text { Hiperte } \\
\text { xtos }\end{array}$ & $\begin{array}{c}\text { Imag } \\
\text { ens }\end{array}$ & $\begin{array}{c}\text { Map } \\
\text { as }\end{array}$ & $\begin{array}{c}\text { Softwares } \\
\text { Educacionais }\end{array}$ & $\begin{array}{c}\text { Víde } \\
\text { os }\end{array}$ & $\begin{array}{c}\text { Total } \\
\text { Geral }\end{array}$ \\
\hline Quantidades & $\mathbf{2 5}$ & $\mathbf{0}$ & $\mathbf{4}$ & $\mathbf{0}$ & $\mathbf{1}$ & $\mathbf{0}$ & $\mathbf{0}$ & $\mathbf{5}$ & $\mathbf{3 5}$ \\
\hline
\end{tabular}

Fonte: Próprio autor (2016)

Quanto os objetos Áudios, Experimentos Práticos, Hipertextos, Mapas, Softwares Educativos e Vídeos disponíveis do BIOE, observa-se uma menor quantidade em comparação aos simuladores.

Os resultados deste trabalho visam apresentar para alunos e professores os objetos de aprendizagem para o ensino superior de química disponíveis no Banco Internacional de Objetos Educacionais que possam ser utilizados para a melhoria do processo de ensino aprendizagem na disciplina Química Geral I, descrevendo também a maneira de como acessálos de forma gratuita. Já dito duas vezes

RPI Revista de Pesquisa Interdisciplinar, Cajazeiras, v. 1, Ed. Especial, 390 - 401, set/dez. de 2016. 


\section{Conclusão}

Diante dos objetivos propostos no presente trabalho realizou-se uma pesquisa de maneira quantitativa e qualitativa dos objetos educacionais disponíveis no (BIOE), para o ensino superior de Química, com enfoque nos conteúdos da disciplina Química Geral I.

O BIOE disponibiliza 370 objetos para o Ensino Superior de Química, desenvolvidos com o objetivo de auxiliar os profissionais do âmbito educacional, como método de busca de recursos digitais, que propiciem facilidade ao acesso e aquisição dos conteúdos pelos educandos. Para a componente curricular Química Geral I, as categorias Animações/Simulações apresentam um numero maior de objetos de 25, no entanto, outras categorias apresentam deficiência dos objetos, como caso dos experimentos práticos (0), imagens (1), softwares educativos (0) e mapas (0).

A presente pesquisa contribui para que professores e/ou alunos tomem conhecimento dos objetos educacionais disponíveis no BIOE que podem ser usados na disciplina Química Geral I no ensino superior de química e dessa forma, possam utilizá-los como auxilio no processo de ensino aprendizagem nas aulas de química.

\section{REFERÊNCIAS BIBLIOGRAFICAS}

AREA, M. Vinte anos de políticas institucionais para incorporar as tecnologias da informação e comunicação ao sistema escolar. In:SANCHO, J. M; HERNÁNDEZ, F. Tecnologias para transformar a educação. Porto Alegre: Artmed, 2006. p.153-175.

FONSECA, J. J. S. Metodologia da pesquisa científica. Apostila. Fortaleza: UEC, 2002.

GIL, A. C. Métodos e técnicas de pesquisa social. 6. ed. São Paulo: Atlas, 2008.

PRODANOV, Cleber Cristiano; FREITAS, Ernani Cesar de. Metodologia do trabalho científico: métodos e técnicas da pesquisa e do trabalho acadêmico. 2 ed. Novo Hamburgo: Feevale, 2013.

LEITE, Fernando César Lima. Como gerenciar e ampliar a visibilidade da informação científica brasileira: repositórios institucionais de acesso aberto. Brasília: IBICT, 2009. 124 p. Disponível em: <http://www.ibict.br/anexos_noticias/repositorios.institucionais.F.Leite_ atualizado.pdf $>$. Acesso em: 02 Jun. 2016.

RODRIGUES, Nara Caetano. TECNOLOGIAS DE INFORMAÇÃO E COMUNICAÇÃO NA EDUCAÇÃO: um desafio na prática docente. Fórum Lingüístico, Florianópolis, v.6, n.1 (1-22), jan-jun, 2009. 
ZUCCO, César; PESSINE, Francisco B.T; ANDRADE, Jailson B. de. Diretrizes Curriculares para os Cursos de Licenciatura em Química*. Química Nova. 22(3) (1999).

RPI Revista de Pesquisa Interdisciplinar, Cajazeiras, v. 1, Ed. Especial, 390 - 401, set/dez. de 2016. 